\title{
Association between Endothelial Dysfunction and Acute Brain Dysfunction during Critical IIIness
}

Christopher G. Hughes, MD1 , Alessandro Morandi, MD², Timothy D. Girard, MD ${ }^{3}$, Bernhard Riedel, MD, PhD ${ }^{4}$, Jennifer L. Thompson, MPH ${ }^{5}$, Ayumi K. Shintani, $\mathrm{PhD}^{6}$, Brenda T. Pun, MSN $^{7}$, E. Wesley Ely, MD $^{8}$, and Pratik P. Pandharipande, MD $^{9}$

${ }^{1}$ Assistant Professor, Department of Anesthesiology, Division of Critical Care, Vanderbilt University School of Medicine

${ }^{2}$ Geriatric Consultant, Rehabilitation and Aged Care Unit, Ancelle della Carità Brescia; Center for Health Services Research, Vanderbilt University School of Medicine

${ }^{3}$ Assistant Professor, Department of Medicine, Division of Pulmonary and Critical Care Medicine and Center for Health Services Research, Vanderbilt University School of Medicine; Geriatric Research, Education and Clinical Center Service, Department of Veterans Affairs Medical Center, Tennessee Valley Health Care System

${ }^{4}$ Director of Anesthetics, Department of Anesthesiology, Peter MacCallum Cancer Centre and University of Melbourne

${ }^{5}$ Biostatistician, Department of Biostatistics, Vanderbilt University School of Medicine

${ }^{6}$ Associate Professor, Department of Biostatistics, Vanderbilt University School of Medicine

${ }^{7}$ Project Clinical Manager, Center for Health Services Research, Vanderbilt University School of Medicine; Geriatric Research, Education and Clinical Center Service, Department of Veterans Affairs Medical Center, Tennessee Valley Health Care System Care System

${ }^{8}$ Professor, Department of Medicine, Division of Pulmonary and Critical Care Medicine and Center for Health Services Research, Vanderbilt University School of Medicine; Geriatric Research, Education and Clinical Center Service, Department of Veterans Affairs Medical Center, Tennessee Valley Health Care System

${ }^{9}$ Associate Professor, Anesthesia Service, Veterans Affairs Medical Center, Tennessee Valley Health Care System and Department of Anesthesiology, Division of Critical Care, Vanderbilt University School of Medicine

Corresponding Author: Christopher G. Hughes, M.D., $121121^{\text {st }}$ Ave. South, 526 MAB, Nashville, TN 37212, P: 615-936-2454, F: 615-343-6272, christopher.hughes@ vanderbilt.edu.

Attribution:

Department of Anesthesiology, Vanderbilt University School of Medicine

Meetings at which the work has been presented:

Society of Critical Care Medicine's $41^{\text {st }}$ Critical Care Congress. February 6, 2012. Houston, Texas.

American Society of Anesthesiologists Anesthesiology 2011 Annual Meeting. October 14, 2011. Chicago, Illinois.

Disclosure of Funding:

Dr. Hughes receives salary support from a Foundation for Anesthesia Education and Research (Rochester, Minnesota, USA) Mentored Research Training Grant. Dr. Ely is supported by the VA Clinical Science Research and Development Service (Washington, District of Columbia, USA) and the National Institutes of Health AG027472 (Bethesda, Maryland, USA). Dr. Girard is supported by the National Institutes of Health AG034257 (Bethesda, Maryland, USA). Drs. Ely and Girard are both supported by the Veterans Affairs Tennessee Valley Geriatric Research, Education and Clinical Center (Nashville, Tennessee, USA). Dr. Riedel is supported by an International Anesthesia Research Society (San Francisco, California, USA) Clinical Scholar Grant. This project was supported by a Vanderbilt Clinical and Translational Science Award grant UL1 RR024975 from the National Institutes of Health (Bethesda, Maryland, USA), Innovation Grant from Vanderbilt University Department of Anesthesiology (Nashville, Tennessee, USA), and National Institutes of Health AG027472 (Bethesda, Maryland, USA). 


\section{Abstract}

Background-Acute brain dysfunction (delirium and coma) during critical illness is prevalent and costly, but the pathophysiology remains unclear. The relationship of acute brain dysfunction with endothelial function, which is impaired in critical illness and may contribute to alterations in cerebral blood flow and blood-brain barrier permeability, has not been studied. We sought to determine whether systemic endothelial dysfunction is associated with acute brain dysfunction during critical illness.

Methods-In this prospective cohort study, we enrolled adult medical/surgical intensive care unit patients in shock and/or respiratory failure. We assessed endothelial function at enrollment using peripheral artery tonometry to calculate the reactive hyperemia index, with lower reactive hyperemia index indicative of worse endothelial function. Patients were assessed for coma and delirium with the Richmond Agitation-Sedation Scale and Confusion Assessment Method for the Intensive Care Unit. We used multivariable linear regression to analyze the association between reactive hyperemia index and 1) delirium/coma-free days among all patients and 2) delirium duration among survivors, both over 14 days.

Results-We enrolled 147 patients with median age of 57 years and median Acute Physiology and Chronic Health Evaluation II score of 26. After adjusting for age, severity of illness, severe sepsis, preexisting cognitive function, medical vs. surgical intensive care unit admission, and prehospital statin use, lower reactive hyperemia index (worse systemic endothelial function) was associated with fewer delirium/coma-free days $(\mathrm{p}=0.02)$ and more delirium days $(\mathrm{p}=0.05)$.

Conclusions-In this study, critically ill patients with lower vascular reactivity indicative of worse systemic endothelial function had increased duration of acute brain dysfunction.

\section{Introduction}

Acute brain dysfunction (delirium and coma) during critical illness is highly prevalent and independently associated with prolonged mechanical ventilation, longer and more costly hospitalizations, increased risk of cognitive dysfunction months after hospital discharge, and higher mortality. ${ }^{1-7}$ The leading mechanisms thought to explain the pathogenesis of this acute brain dysfunction, such as inflammation, abnormal cerebral blood flow, and increased blood-brain barrier permeability, ${ }^{8 ; 9}$ each involve the endothelium, a dynamic component of the blood-brain barrier with vasomotor and biochemical properties.

In critical illness states such as sepsis and multiple organ dysfunction syndrome, circulating inflammatory cytokines affect the endothelium's expression of adhesion molecules, signaling pathways, and nitric oxide production..$^{10 ; 11}$ This further results in coagulation system activation, altered perfusion, distorted permeability, and decreased ability for vascular repair. ${ }^{12 ; 13}$ In the brain specifically, structural and functional alterations of bloodbrain barrier endothelial cells secondary to inflammatory states have been associated with increased microvascular permeability and impaired microcirculatory blood flow. ${ }^{14-17}$

Given the relationships between endothelial dysfunction and potential mechanisms of brain dysfunction during critical illness, we hypothesized that critically ill patients with systemic vascular endothelial dysfunction would be at greater risk for acute brain dysfunction (Figure 1). To test this hypothesis, we assessed endothelial function via a reactive hyperemia technique with peripheral artery tonometry in medical and surgical intensive care unit (ICU) patients and prospectively assessed them for delirium and coma. 


\section{Materials and Methods}

\section{Study Design and Population}

This prospective cohort study was nested within a larger observational study evaluating long-term cognitive impairment in survivors of critical illness. In a protocol approved by the Vanderbilt University Institutional Review Board (Nashville, Tennessee), critically ill adults consecutively admitted to the medical or surgical ICU at Vanderbilt University Medical Center with respiratory failure and/or shock were considered for inclusion in this study. Exclusion criteria for the parent study included severe cognitive or neurodegenerative disease that prevented independent living at baseline, ICU admission for neurological insult or post-cardiopulmonary resuscitation with suspected anoxic brain injury, active substance abuse or psychotic disorder, blindness, deafness, inability to speak English, moribund with life expectancy $<24$ hours, onset of the current episode of respiratory failure or shock $>72$ hours prior to enrollment, and cardiac surgery within the past 3 months. Additional exclusion criteria for this study of endothelial function included upper extremity injury, presence of arteriovenous fistula, prone positioning, and unavailability of equipment/ technician within 24 hours of enrollment. After obtaining informed consent from the patient or an authorized surrogate, baseline endothelial function and daily brain dysfunction monitoring were performed as detailed in the following sections.

\section{Endothelial Function Assessment}

Systemic endothelial function was assessed within 24 hours of study enrollment by a reactive hyperemia technique using peripheral artery tonometry via the Endo_PAT device (Itamar Medical Ltd, Franklin, MA) to determine vascular reactivity. Originally validated against coronary angiography, ${ }^{18 ; 19}$ the Endo_PAT has also been used to evaluate endothelial function in patients with coronary artery disease, atherosclerosis, hypertension, congestive heart failure, schizophrenia, sepsis, and many other disease processes. ${ }^{20-25}$

With the participant lying supine in bed with both hands located at the level of the heart, a pneumatic finger probe was placed on each hand to perform a plethysmographic recording of the finger arterial pulse wave amplitude. Baseline pulse wave amplitude measurements were obtained for 5 minutes. A blood pressure cuff was then inflated on one arm to a suprasystolic pressure ( $50 \mathrm{~mm} \mathrm{Hg}$ above systolic pressure), and complete occlusion of the tonometry signal was confirmed to minimize error from inaccurate pre-test blood pressure readings. The other arm remained unoccluded to serve as the reference. Five minutes after the cuff was inflated, it was released to induce reactive hyperemia, and pulse wave amplitude was measured for an additional 5 minutes. With this technique, the reactive hyperemia index (RHI) is calculated by the Endo_PAT as the ratio between the magnitude of the average post-occlusive pulse wave amplitude and the average baseline pulse wave amplitude, corrected to systemic changes seen in the unoccluded arm. The Endo_PAT measurements and calculations use a computerized algorithm that requires no specific input from the technician, thereby reducing observer variability. A lower RHI indicates worse endothelial function, with values $<1.67$ considered to represent endothelial dysfunction. ${ }^{18 ; 19}$ The Endo_PAT technician was blinded to results of brain dysfunction assessments done by research personnel, and the research personnel performing brain dysfunction assessments were blinded to RHI results.

\section{Brain Dysfunction Monitoring}

A trained research nurse or assistant assessed every patient for acute brain dysfunction (coma and delirium) twice per day in the ICU and once per day on the ward using the Richmond Agitation-Sedation Scale and Confusion Assessment Method for the ICU, as per our standardized online ${ }^{*}$ manual. ${ }^{2 ; 26}$ Assessments were performed until death, hospital 
discharge, or 14 days post enrollment, whichever occurred first. By definition, patients were considered delirious if they were not comatose (e.g., had a Richmond Agitation-Sedation Scale score of -3 or more awake) and were Confusion Assessment Method for the ICU positive. Coma was defined as a Richmond Agitation-Sedation Scale score of -4 (responsive to physical stimulus only) or -5 (completely unresponsive).

\section{Statistical Analysis}

To effectively examine the association between systemic endothelial dysfunction and acute brain dysfunction while accounting for bias due to death, we used the number of days alive and without delirium or coma (e.g., delirium/coma-free days) during the 14 days after study enrollment as our primary outcome (dependent variable). Patients who were discharged from the hospital prior to study day 14 were assumed to be non-delirious for days after discharge. In order to examine the association between endothelial dysfunction and delirium specifically, we used a secondary outcome of duration of delirium over this same 14-day period. We designated this a secondary analysis a priori and included only survivors because early death would curtail delirium duration and bias results of this analysis.

We used multivariable linear regression to assess the independent association of systemic endothelial function, as assessed by Endo_PAT RHI, with the primary and secondary outcomes, after adjusting for relevant covariates. These covariates were chosen a priori based on prior research and clinical judgment and included age, severity of illness as measured by acute physiology score of the Acute Physiology and Chronic Health Evaluation $\mathrm{II}^{27}$ score, severe sepsis at ICU admission defined as known or suspected infection with two or more systemic inflammatory response syndrome criteria and presence of organ dysfunction (mechanical ventilation and/or vasopressor requirement), preexisting cognitive function as measured by the Informant Questionnaire on Cognitive Decline in the Elderly ${ }^{28}$ score, medical vs. surgical ICU admission, and prehospital statin use. Delirium/coma-free days have a bimodal distribution and, as such, present a challenge in statistical modeling. Our biostatisticians (JLT, AKS) therefore performed simulations to assess the suitability of using linear regression, proportional odds logistic regression, and several other strategies to model delirium/coma-free days. The results of the simulations showed that linear regression performed reliably and had the most power of any method. Given these results, and that many clinicians are familiar with linear regression, we have chosen to use that as our primary analysis. All continuous variables, including Endo_PAT RHI, were initially allowed to have a nonlinear relationship with the outcome, using restricted cubic splines. If there was evidence that an association was nonlinear, (e.g., the $\mathrm{p}$ for nonlinearity was $<0.20$ ), the nonlinear term was retained in the model; otherwise, the nonlinear terms were removed for parsimony. We chose to report the adjusted difference in outcomes between the $25^{\text {th }}$ and $75^{\text {th }}$ percentile Endo_PAT RHI values of our population rather than the difference in outcomes per each single-unit change in Endo_PAT RHI given that single-unit changes in vascular reactivity endothelial function assessments are not clinically meaningful. We used $\mathrm{R}$ version 2.15 .1 for all statistical analyses. ${ }^{29}$

The sample size for this nested cohort was based on the primary outcome of days alive and without delirium or coma (delirium/coma-free days), modeled using multivariable linear regression with the variables listed in the previous paragraph. Continuous variables required two degrees of freedom for non-linearity, while dichotomous variables required one degree of freedom. Therefore, the minimum degrees of freedom required for the model was 11. Assuming that one degree of freedom required 15 patients in order to reliably fit the model,

*www.ICUdelirium.org (June 5, 2012) 
a multivariable model with a complexity of 11 degrees of freedom requires an effective sample size of $11 \times 15=165$ subjects. ${ }^{30}$

\section{Results}

From April 2009 to September 2010, 178 patients were consented and enrolled into the parent study (Figure 2). Thirty-one of these patients met additional exclusion criteria for peripheral artery tonometry endothelial function assessment. As a result, 147 patients participated in endothelial function assessments in this study.

Patient characteristics and outcomes are presented in Table 1, showing that the study population had a high severity of illness, with a median Acute Physiology and Chronic Health Evaluation II score of 26 and frequent organ dysfunctions. Additionally, $30 \%$ of patients had severe sepsis at admission, and $85 \%$ were mechanically ventilated at study enrollment. Acute brain dysfunction was also common, with $70 \%$ of patients having delirium at some point during the 14-day study period. The median duration of delirium was 2 days, and the median duration of coma was 1 day.

Systemic endothelial function was successfully assessed by Endo_PAT RHI in 134 patients who had a median (interquartile range) RHI of 1.51 (1.32-1.81). For 13 patients who were assessed with the Endo_PAT, the device was unable to provide satisfactory RHI evaluations (Figure 2). There were no significant differences in the demographic data between patients in whom RHI was vs. was not successfully measured.

After adjusting for age, severity of illness, severe sepsis at admission, preexisting cognitive function, medical vs. surgical ICU admission, and prehospital statin use, worse systemic endothelial function - indicated by a lower RHI as measured by the Endo_PAT wasindependently associated with fewer delirium/coma-free days $(\mathrm{p}=0.02$; Table 2 and Figure 3). Other covariates being equal, for example, a patient with a RHI of 1.32 (the $25^{\text {th }}$ percentile in our study population) would have, on average, 0.8 fewer delirium/coma-free days during the 14-day study period (95\% CI: $-1.54,-0.12 ; \mathrm{p}=0.02)$ than a patient with a RHI of 1.81 (the $75^{\text {th }}$ percentile). Worse systemic endothelial function was also marginally associated with increased duration of delirium in the 113 survivors ( $\mathrm{p}=0.05$; Table 3 and Figure 4). Similarly as above, a patient with a RHI of $1.32\left(25^{\text {th }}\right.$ percentile) would have, on average, 0.4 more days of delirium during the study period (95\% CI: $0.00,0.86 ; \mathrm{p}=0.05$ ) than a patient with a RHI of $1.81\left(75^{\text {th }}\right.$ percentile).

In addition to worse endothelial function, older age and higher severity of illness (measured by the acute physiology score of the Acute Physiology and Chronic Health Evaluation II score) were also independently associated with fewer delirium/coma-free days in all patients (Table 2) and increased delirium duration in survivors (Table 3), consistent with previous studies. ${ }^{31-33}$ A sensitivity analysis adjusting for underlying vascular disease, as defined by the Framingham Stroke Risk Profile, ${ }^{34}$ still found a significant association between Endo_PAT RHI and delirium/coma-free days $(\mathrm{p}=0.04)$, though the association with delirium days was marginal $(\mathrm{p}=0.06)$.

\section{Discussion}

In this study, the first to examine the potential relationship of systemic endothelial dysfunction and acute brain dysfunction during critical illness, we found that impaired vascular reactivity indicative of worse systemic endothelial function was independently associated with fewer delirium/coma-free days. This association is consistent with the hypothesis that endothelial dysfunction plays a role in the pathogenesis of acute brain dysfunction during critical illness. Thus, this investigation should prompt further studies to 
examine mechanisms whereby endothelial dysfunction may contribute to the pathogenesis of brain dysfunction in the critically ill.

Despite increasing research in the field, the complex pathophysiology of acute brain dysfunction in the critically ill remains elusive. Multiple hypotheses have been developed, with many centering on the effects of inflammation in the brain. ${ }^{35 ; 36}$ The hypothesis we propose herein, that endothelial dysfunction contributes to acute brain dysfunction during critical illness, is not an alternative but rather a complement to the inflammation hypothesis of acute brain dysfunction during critical illness. In sepsis, the prototypical example of an inflammatory state during critical illness, inflammatory mediators have been shown to bind directly to receptors on the endothelium, leading to cell detachment, cell death, altered vascular function, microvascular injury, and altered organ perfusion. ${ }^{12 ; 13}$ In the brain, reduced blood flow and increased vascular permeability during sepsis lead to neuronal inflammation and tissue damage, modulating synthesis of neurotransmitters and altering expression of neurotransmitter receptors. ${ }^{35-37}$ Given that the blood-brain barrier consists of endothelial cells, along with astrocyte foot processes, it is plausible that patients with endothelial dysfunction may have an exaggeration of such responses. Altered endothelial vasomotor function and increased expression of adhesion molecules and coagulation mediators from endothelial activation may lead to altered perfusion, distorted permeability, thrombosis, and decreased ability for repair that contribute to the development of brain organ dysfunction. If so, a reliable measure of systemic endothelial function may act as a noninvasive surrogate for blood-brain barrier function involved in brain dysfunction during critical illness.

Reactive hyperemia is a noninvasive technique to assess endothelial function. During reactive hyperemia, endothelial nitric oxide release mediates changes in vascular tone and blood flow. Using validated tools, such as peripheral artery tonometry and brachial artery reactivity testing, investigators and clinicians can measure these changes in vascular reactivity and thereby assess endothelial function at the bedside. ${ }^{18 ; 19 ; 38}$ Attenuations in reactive hyperemia and other endothelial-dependent dilator responses indicate endothelial dysfunction and have been associated with poor cardiovascular and cerebrovascular outcomes, severity of sepsis, and mortality during critical illness. ${ }^{20 ; 39-43}$ In previous studies, systemic endothelial function has been evaluated using several methods, including flowmediated dilation of the brachial artery as a response to reactive hyperemia, aortic augmentation index requiring arterial cannulation and vasodilator administration, and laser Doppler plethysmography also requiring vasodilator administration. ${ }^{39 ; 43 ; 44}$ Because these methods are invasive or require skilled operators, we chose to utilize the Endo_PAT device, which relies on peripheral artery tonometry to calculate the RHI, a validated assessment of endothelial function. The device is easy to use, noninvasive, portable, and utilizes a computerized algorithm to assess function.

The results of our study are consistent with those of prior studies showing that endothelial function is worse in the setting of disease and acute illness. Whereas the majority of healthy patients with few or no cardiac risk factors have average RHI values greater than 2.2, those with coronary artery disease (2.0), sepsis without organ failure (1.85), and sepsis with organ failure (1.57) show progressively worsening endothelial function. ${ }^{20 ; 25}$ Our cohort, consisting of ICU patients with shock and/or respiratory failure, had a median RHI of 1.51, suggesting even poorer endothelial function than that previously reported. The results of our study, along with those of Davis and colleagues, ${ }^{20}$ support that endothelial function assessments with the Endo_PAT can be performed at the bedside in critically ill patients. Thus, if future studies confirm that Endo_PAT RHI measurements are associated with patients' acute cognitive outcomes, endothelial function monitoring may serve as a prognostic tool in the ICU as well as a means to study the impact of therapies aimed at 
reducing brain dysfunction through interventions that enhance endothelial function (e.g., statin pharmacotherapy, early physical rehabilitation). ${ }^{45}$

Our results are also in agreement with the growing body of literature examining tissue perfusion abnormalities as measured by near-infrared spectroscopy. Consistently low tissue oxygenation was associated with worse organ failure in small cohorts of critically ill patients, ${ }^{46}$ and lower tissue oxygen saturation and slower recovery rate after an ischemic period has been correlated to perfusion abnormaities. ${ }^{47}$ In addition, abnormal tissue oxygenation recovery after an ischemic period has been demonstrated in patients with sepsis and is more pronounced in patients with septic shock. ${ }^{48 ; 49}$ Data with regards to brain dysfunction are still evolving, as cerebral tissue oxygenation was not associated with sepsisassociated delirium ${ }^{50}$ but lower preoperative cerebral tissue oxygenation was associated with postoperative delirium in another small cohort study. ${ }^{51}$

Our study has several strengths and limitations. Since many conditions (e.g., genetic makeup, comorbid diseases including prior vascular disease, current critical illness) affect the endothelium, we examined the culmination of these effects by assessing endothelial function at enrollment. Importantly, we found the association between endothelial function and duration of brain dysfunction to remain significant even when vascular comorbid disease burden was included in the sensitivity analysis. We relied on a functional assessment of systemic endothelial vasomotor performance (rather than a static lab value of endothelial injury) and showed that active endothelial dysfunction was associated with worse brain dysfunction outcomes, independent of age, severity of illness, or vascular risk factors. It is possible that factors associated with critical illness (e.g., disease processes, therapeutics) might differently affect endothelial vasomotor function and endothelial injury resulting in biomarker release, an area of particular interest in the pathophysiology of inflammatory disease states such as sepsis. ${ }^{52 ; 53}$

The single-center design may limit generalizability to only patient populations similar to ours; however, we enrolled a heterogeneous population by including medical and surgical ICU patients with a broad range of diagnoses. Our study is also the largest to use the Endo_PAT device to assess endothelial function in critically ill patients. Poor signal quality for peripheral artery tonometry prevented a RHI measurement during only $9(6 \%)$ of 147 studies performed, despite the majority of patients receiving sedatives, vasopressors, and/or mechanical ventilation during their evaluation. Lack of patient cooperation prevented another 3 RHI measurements, raising the question of whether patients with hyperactive delirium can be assessed with the Endo_PAT; this scenario was very rare, however, in keeping with studies showing that pure hyperactive delirium is uncommon in critically ill patients. ${ }^{54}$ Upper extremity defects or prone positioning also prevented the performance of peripheral artery tonometry, but this was rare; however, radial arterial catheters which are common in the ICU did not affect the ability to obtain RHI measurements. Given the pilot nature of this study, the first to examine the association between systemic endothelial function and acute brain dysfunction, we only assessed endothelial function at one time point (enrollment) to test our hypothesis. Serial assessments would have provided an indication of how endothelial alterations evolve during critical illness and in patients with acute brain dysfunction and should be considered in future studies.

Though our study was larger than earlier investigations of endothelial vasomotor function during critical illness, a larger sample size would improve statistical power and allow the inclusion of additional potential confounders, such as specific comorbidities, inflammatory mediators, and exposure to vasoactive or sedative medications. When required, vasopressor agents were administered to patients via central venous access, thus causing systemic (not local) effects, which are accounted for in the RHI calculations by inclusion of baseline pulse 
wave amplitudes and pulse wave amplitudes from the reference unobstructed arm.

Measurements were also taken during steady state infusion and not during drug bolus.

Furthermore, prior research suggests the RHI itself is unlikely to be significantly altered by vasopressor administration. ${ }^{55-57}$ Future studies examining the role of endothelial

dysfunction in brain dysfunction outcomes, however, need to evaluate potential mechanisms of mediation, including inflammation, markers of endothelial injury, and therapeutics such as sedation.

\section{Conclusions}

In this prospective cohort study of severely ill medical and surgical ICU patients, we found that impaired vascular reactivity indicative of worse systemic endothelial function was independently associated with acute brain dysfunction. Though our study was not intended to and cannot show a mechanistic relationship between endothelial dysfunction and acute brain dysfunction, our findings lend support to the hypothesis that endothelial dysfunction plays a role in the pathogenesis of acute brain dysfunction during critical illness. In light of these findings, subsequent investigations are needed to examine specific mechanisms (e.g., disruption of the blood-brain barrier or cerebral blood flow) whereby endothelial dysfunction may contribute to the pathogenesis of brain dysfunction during critical illness. Such studies could point to therapies that modify endothelial function and thereby improve short- and long-term neurologic outcomes in critically ill patients.

\section{References}

1. Ely EW, Gautam S, Margolin R, Francis J, May L, Speroff T, Truman B, Dittus R, Bernard R, Inouye SK. The impact of delirium in the intensive care unit on hospital length of stay. Intensive Care Med. 2001; 27:1892-900. [PubMed: 11797025]

2. Ely EW, Inouye SK, Bernard GR, Gordon S, Francis J, May L, Truman B, Speroff T, Gautam S, Margolin R, Hart RP, Dittus R. Delirium in mechanically ventilated patients: validity and reliability of the confusion assessment method for the intensive care unit (CAM-ICU). JAMA. 2001; 286:2703-10. [PubMed: 11730446]

3. Ely EW, Shintani A, Truman B, Speroff T, Gordon SM, Harrell FE Jr, Inouye SK, Bernard GR, Dittus RS. Delirium as a predictor of mortality in mechanically ventilated patients in the intensive care unit. JAMA. 2004; 291:1753-62. [PubMed: 15082703]

4. Girard TD, Jackson JC, Pandharipande PP, Pun BT, Thompson JL, Shintani AK, Gordon SM, Canonico AE, Dittus RS, Bernard GR, Ely EW. Delirium as a predictor of long-term cognitive impairment in survivors of critical illness. Crit Care Med. 2010; 38:1513-20. [PubMed: 20473145]

5. Milbrandt EB, Deppen S, Harrison PL, Shintani AK, Speroff T, Stiles RA, Truman B, Bernard GR, Dittus RS, Ely EW. Costs associated with delirium in mechanically ventilated patients. Crit Care Med. 2004; 32:955-62. [PubMed: 15071384]

6. Pisani MA, Kong SY, Kasl SV, Murphy TE, Araujo KL, Van Ness PH. Days of delirium are associated with 1-year mortality in an older intensive care unit population. Am J Respir Crit Care Med. 2009; 180:1092-7. [PubMed: 19745202]

7. Shehabi Y, Riker RR, Bokesch PM, Wisemandle W, Shintani A, Ely EW. Delirium duration and mortality in lightly sedated, mechanically ventilated intensive care patients. Crit Care Med. 2010; 38:2311-8. [PubMed: 20838332]

8. Girard TD, Pandharipande PP, Ely EW. Delirium in the intensive care unit. Crit Care. 2008; 12 (Suppl 3):S3. [PubMed: 18495054]

9. Sharshar T, Carlier R, Bernard F, Guidoux C, Brouland JP, Nardi O, de la Grandmaison GL, Aboab J, Gray F, Menon D, Annane D. Brain lesions in septic shock: A magnetic resonance imaging study. Intensive Care Med. 2007; 33:798-806. [PubMed: 17377766]

10. Aird WC. The role of the endothelium in severe sepsis and multiple organ dysfunction syndrome. Blood. 2003; 101:3765-77. [PubMed: 12543869] 
11. Shapiro NI, Schuetz P, Yano K, Sorasaki M, Parikh SM, Jones AE, Trzeciak S, Ngo L, Aird WC. The association of endothelial cell signaling, severity of illness, and organ dysfunction in sepsis. Crit Care. 2010; 14:R182. [PubMed: 20942957]

12. Ait-Oufella H, Maury E, Lehoux S, Guidet B, Offenstadt G. The endothelium: Physiological functions and role in microcirculatory failure during severe sepsis. Intensive Care Med. 2010; 36:1286-98. [PubMed: 20443110]

13. Sakr Y, Dubois MJ, De BD, Creteur J, Vincent JL. Persistent microcirculatory alterations are associated with organ failure and death in patients with septic shock. Crit Care Med. 2004; 32:1825-31. [PubMed: 15343008]

14. Abbott NJ, Ronnback L, Hansson E. Astrocyte-endothelial interactions at the blood-brain barrier. Nat Rev Neurosci. 2006; 7:41-53. [PubMed: 16371949]

15. Gavins F, Yilmaz G, Granger DN. The evolving paradigm for blood cell-endothelial cell interactions in the cerebral microcirculation. Microcirculation. 2007; 14:667-81. [PubMed: 17885993]

16. He F, Peng J, Deng XL, Yang LF, Wu LW, Zhang CL, Yin F. RhoA and NF-kappaB are involved in lipopolysaccharide-induced brain microvascular cell line hyperpermeability. Neuroscience. 2011; 188:35-47. [PubMed: 21575689]

17. Taccone FS, Su F, Pierrakos C, He X, James S, Dewitte O, Vincent JL, De BD. Cerebral microcirculation is impaired during sepsis: An experimental study. Crit Care. 2010; 14:R140. [PubMed: 20667108]

18. Bonetti PO, Pumper GM, Higano ST, Holmes DR Jr, Kuvin JT, Lerman A. Noninvasive identification of patients with early coronary atherosclerosis by assessment of digital reactive hyperemia. J Am Coll Cardiol. 2004; 44:2137-41. [PubMed: 15582310]

19. Kuvin JT, Patel AR, Sliney KA, Pandian NG, Sheffy J, Schnall RP, Karas RH, Udelson JE. Assessment of peripheral vascular endothelial function with finger arterial pulse wave amplitude. Am Heart J. 2003; 146:168-74. [PubMed: 12851627]

20. Davis JS, Yeo TW, Thomas JH, McMillan M, Darcy CJ, McNeil YR, Cheng AC, Celermajer DS, Stephens DP, Anstey NM. Sepsis-associated microvascular dysfunction measured by peripheral arterial tonometry: An observational study. Crit Care. 2009; 13:R155. [PubMed: 19778457]

21. Ellingrod VL, Taylor SF, Brook RD, Evans SJ, Zollner SK, Grove TB, Gardner KM, Bly MJ, PopBusui R, Dalack G. Dietary, lifestyle and pharmacogenetic factors associated with arteriole endothelial-dependent vasodilatation in schizophrenia patients treated with atypical antipsychotics (AAPs). Schizophr Res. 2011; 130:20-6. [PubMed: 21504842]

22. Fitch KV, Stavrou E, Looby SE, Hemphill L, Jaff MR, Grinspoon SK. Associations of cardiovascular risk factors with two surrogate markers of subclinical atherosclerosis: Endothelial function and carotid intima media thickness. Atherosclerosis. 2011; 217:437-40. [PubMed: 21570076]

23. Hamburg NM, Keyes MJ, Larson MG, Vasan RS, Schnabel R, Pryde MM, Mitchell GF, Sheffy J, Vita JA, Benjamin EJ. Cross-sectional relations of digital vascular function to cardiovascular risk factors in the Framingham Heart Study. Circulation. 2008; 117:2467-74. [PubMed: 18458169]

24. Matsuzawa Y, Sugiyama S, Sugamura K, Nozaki T, Ohba K, Konishi M, Matsubara J, Sumida H, Kaikita K, Kojima S, Nagayoshi Y, Yamamuro M, Izumiya Y, Iwashita S, Matsui K, Jinnouchi H, Kimura K, Umemura S, Ogawa H. Digital assessment of endothelial function and ischemic heart disease in women. J Am Coll Cardiol. 2010; 55:1688-96. [PubMed: 20394872]

25. Kuvin JT, Mammen A, Mooney P, Alsheikh-Ali AA, Karas RH. Assessment of peripheral vascular endothelial function in the ambulatory setting. Vasc Med. 2007; 12:13-6. [PubMed: 17451088]

26. Sessler CN, Gosnell MS, Grap MJ, Brophy GM, O’Neal PV, Keane KA, Tesoro EP, Elswick RK. The Richmond Agitation-Sedation Scale: Validity and reliability in adult intensive care unit patients. Am J Respir Crit Care Med. 2002; 166:1338-44. [PubMed: 12421743]

27. Knaus WA, Draper EA, Wagner DP, Zimmerman JE. APACHE II: A severity of disease classification system. Crit Care Med. 1985; 13:818-29. [PubMed: 3928249]

28. Jorm AF. A short form of the Informant Questionnaire on Cognitive Decline in the Elderly (IQCODE): Development and cross-validation. Psychol Med. 1994; 24:145-53. [PubMed: 8208879] 
29. R Development Core Team. R: A language and environment for statistical computing. R Foundation for Statistical Computing; 2012.

30. Flack V, Chang P. Frequency of selection noise variables in subset regression analysis: A simulation study. American Statistician. 1987; 41:84-6.

31. Dubois MJ, Bergeron N, Dumont M, Dial S, Skrobik Y. Delirium in an intensive care unit: A study of risk factors. Intensive Care Med. 2001; 27:1297-304. [PubMed: 11511942]

32. McNicoll L, Pisani MA, Zhang Y, Ely EW, Siegel MD, Inouye SK. Delirium in the intensive care unit: Occurrence and clinical course in older patients. J Am Geriatr Soc. 2003; 51:591-8. [PubMed: 12752832]

33. Pandharipande P, Cotton BA, Shintani A, Thompson J, Pun BT, Morris JA Jr, Dittus R, Ely EW. Prevalence and risk factors for development of delirium in surgical and trauma intensive care unit patients. J Trauma. 2008; 65:34-41. [PubMed: 18580517]

34. Wang TJ, Massaro JM, Levy D, Vasan RS, Wolf PA, D'Agostino RB, Larson MG, Kannel WB, Benjamin EJ. A risk score for predicting stroke or death in individuals with new-onset atrial fibrillation in the community: The Framingham Heart Study. JAMA. 2003; 290:1049-56. [PubMed: 12941677]

35. Sharshar T, Hopkinson NS, Orlikowski D, Annane D. Science review: The brain in sepsis: Culprit and victim. Crit Care. 2005; 9:37-44. [PubMed: 15693982]

36. Sanders RD. Hypothesis for the pathophysiology of delirium: Role of baseline brain network connectivity and changes in inhibitory tone. Med Hypotheses. 2011; 77:140-3. [PubMed: 21498007]

37. Tsao N, Hsu HP, Wu CM, Liu CC, Lei HY. Tumour necrosis factor-alpha causes an increase in blood-brain barrier permeability during sepsis. J Med Microbiol. 2001; 50:812-21. [PubMed: 11549183]

38. Celermajer DS, Sorensen KE, Gooch VM, Spiegelhalter DJ, Miller OI, Sullivan ID, Lloyd JK, Deanfield JE. Non-invasive detection of endothelial dysfunction in children and adults at risk of atherosclerosis. Lancet. 1992; 340:1111-5. [PubMed: 1359209]

39. Gokce N, Keaney JF Jr, Hunter LM, Watkins MT, Menzoian JO, Vita JA. Risk stratification for postoperative cardiovascular events via noninvasive assessment of endothelial function: a prospective study. Circulation. 2002; 105:1567-72. [PubMed: 11927524]

40. Gokce N, Keaney JF Jr, Hunter LM, Watkins MT, Nedeljkovic ZS, Menzoian JO, Vita JA. Predictive value of noninvasively determined endothelial dysfunction for long-term cardiovascular events in patients with peripheral vascular disease. J Am Coll Cardiol. 2003; 41:1769-75. [PubMed: 12767663]

41. Perticone F, Ceravolo R, Pujia A, Ventura G, Iacopino S, Scozzafava A, Ferraro A, Chello M, Mastroroberto P, Verdecchia P, Schillaci G. Prognostic significance of endothelial dysfunction in hypertensive patients. Circulation. 2001; 104:191-6. [PubMed: 11447085]

42. Targonski PV, Bonetti PO, Pumper GM, Higano ST, Holmes DR Jr, Lerman A. Coronary endothelial dysfunction is associated with an increased risk of cerebrovascular events. Circulation. 2003; 107:2805-9. [PubMed: 12771004]

43. Duffy MJ, Mullan BA, Craig TR, Shyamsundar M, Macsweeney RE, Thompson G, Stevenson M, McAuley DF. Impaired endothelium-dependent vasodilatation is a novel predictor of mortality in intensive care. Crit Care Med. 2011; 39:629-35. [PubMed: 21242802]

44. Kubli S, Boegli Y, Ave AD, Liaudet L, Revelly JP, Golay S, Broccard A, Waeber B, Schaller MD, Feihl F. Endothelium-dependent vasodilation in the skin microcirculation of patients with septic shock. Shock. 2003; 19:274-80. [PubMed: 12630529]

45. Osto E, Coppolino G, Volpe M, Cosentino F. Restoring the dysfunctional endothelium. Curr Pharm Des. 2007; 13:1053-68. [PubMed: 17430168]

46. Lima A, van BJ, Jansen TC, Ince C, Bakker J. Low tissue oxygen saturation at the end of early goal-directed therapy is associated with worse outcome in critically ill patients. Crit Care. 2009; 13 (Suppl 5):S13. [PubMed: 19951385]

47. Lima A, van BJ, Sikorska K, van GM, Klijn E, Lesaffre E, Ince C, Bakker J. The relation of nearinfrared spectroscopy with changes in peripheral circulation in critically ill patients. Crit Care Med. 2011; 39:1649-54. [PubMed: 21685739] 
48. Creteur J, Carollo T, Soldati G, Buchele G, De BD, Vincent JL. The prognostic value of muscle StO2 in septic patients. Intensive Care Med. 2007; 33:1549-56. [PubMed: 17572876]

49. Shapiro NI, Arnold R, Sherwin R, O’Connor J, Najarro G, Singh S, Lundy D, Nelson T, Trzeciak $\mathrm{SW}$, Jones AE. The association of near-infrared spectroscopy-derived tissue oxygenation measurements with sepsis syndromes, organ dysfunction and mortality in emergency department patients with sepsis. Crit Care. 2011; 15:R223. [PubMed: 21939529]

50. Pfister D, Siegemund M, Dell-Kuster S, Smielewski P, Ruegg S, Strebel SP, Marsch SC, Pargger H, Steiner LA. Cerebral perfusion in sepsis-associated delirium. Crit Care. 2008; 12:R63. [PubMed: 18457586]

51. Morimoto Y, Yoshimura M, Utada K, Setoyama K, Matsumoto M, Sakabe T. Prediction of postoperative delirium after abdominal surgery in the elderly. J Anesth. 2009; 23:51-6. [PubMed: 19234823]

52. Kayal S, Jais JP, Aguini N, Chaudiere J, Labrousse J. Elevated circulating E-selectin, intercellular adhesion molecule 1, and von Willebrand factor in patients with severe infection. Am J Respir Crit Care Med. 1998; 157:776-84. [PubMed: 9517590]

53. Ricciuto DR, Dos Santos CC, Hawkes M, Toltl LJ, Conroy AL, Rajwans N, Lafferty EI, Cook DJ, Fox-Robichaud A, Kahnamoui K, Kain KC, Liaw PC, Liles WC. Angiopoietin-1 and angiopoietin-2 as clinically informative prognostic biomarkers of morbidity and mortality in severe sepsis. Crit Care Med. 2011; 39:702-10. [PubMed: 21242795]

54. Pandharipande P, Cotton BA, Shintani A, Thompson J, Costabile S, Truman PB, Dittus R, Ely EW. Motoric subtypes of delirium in mechanically ventilated surgical and trauma intensive care unit patients. Intensive Care Med. 2007; 33:1726-31. [PubMed: 17549455]

55. Nohria A, Gerhard-Herman M, Creager MA, Hurley S, Mitra D, Ganz P. Role of nitric oxide in the regulation of digital pulse volume amplitude in humans. J Appl Physiol. 2006; 101:545-8. [PubMed: 16614356]

56. Rector TS, Bank AJ, De Bruyn VH, Garr MD, Kraemer MD, Kubo SH. Effects of norepinephrine on endothelium-dependent vasodilation of forearm resistance vessels. Clin Pharmacol Ther. 1993; 53:374-9. [PubMed: 8453857]

57. Brown H, Moppett IK, Mahajan RP. Transient hyperaemic response to assess vascular reactivity of skin: effect of locally iontophoresed acetylcholine, bradykinin, epinephrine and phenylephrine. $\mathrm{Br}$ J Anaesth. 2003; 90:446-51. [PubMed: 12644415] 


\section{Summary Statement}

This prospective cohort study found that impaired vascular reactivity indicative of systemic endothelial dysfunction was independently associated with acute brain dysfunction during critical illness, suggesting that the endothelium plays a role in brain dysfunction pathogenesis. 


\section{Final Box Summary}

\section{What we already know about this topic}

- Acute brain dysfunction manifested as delirium and coma is frequent during critical illness, but its pathophysiology remains unclear

- Endothelial function is impaired in critical illness and might contribute to altered cerebral blood flow and blood-brain barrier permeability

\section{What this article tells us that is new}

- Endothelial function was assessed in a prospective cohort study of critically ill patients and its relationship with acute brain dysfunction assessed using multivariable linear regression

- Patients with worse systemic endothelial function had increased duration of acute brain dysfunction 


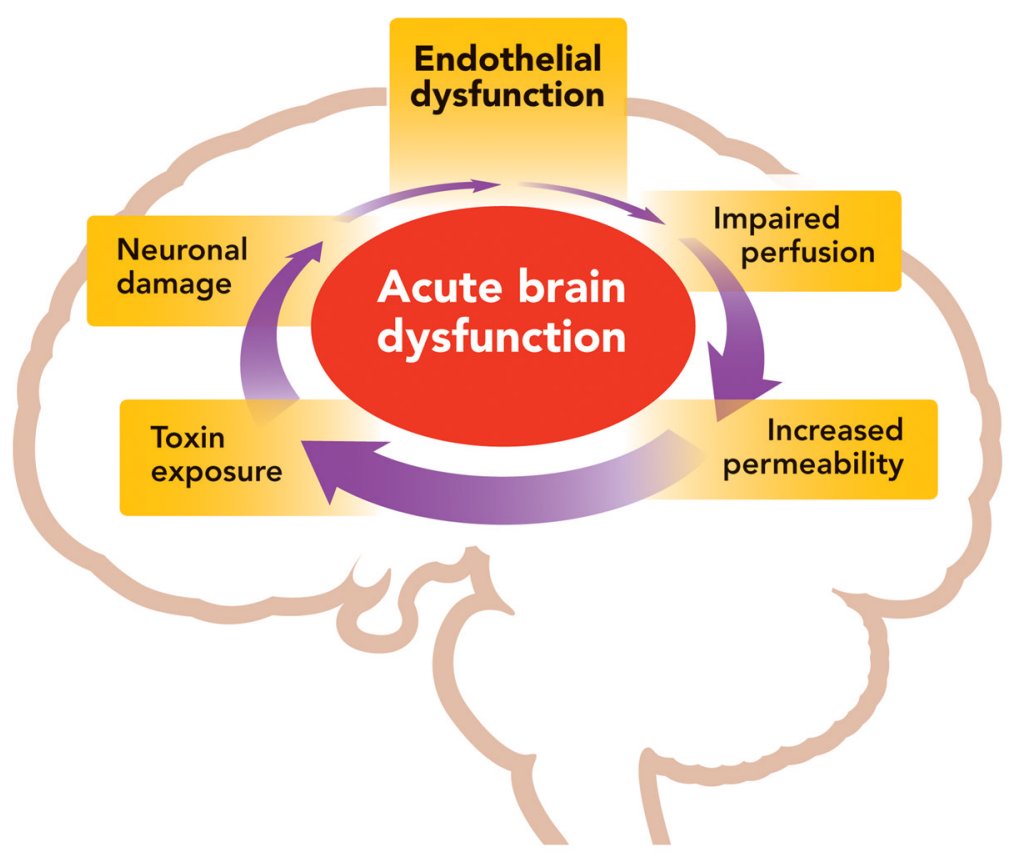

Figure 1. Proposed Relationship between Systemic Endothelial Dysfunction and Acute Brain Dysfunction

Systemic endothelial dysfunction may contribute to impaired cerebral perfusion, increased blood-brain barrier permeability, and exposure of the brain to toxic substances, causing neuronal damage and further brain organ injury. This may present clinically as acute brain dysfunction (delirium and coma). 


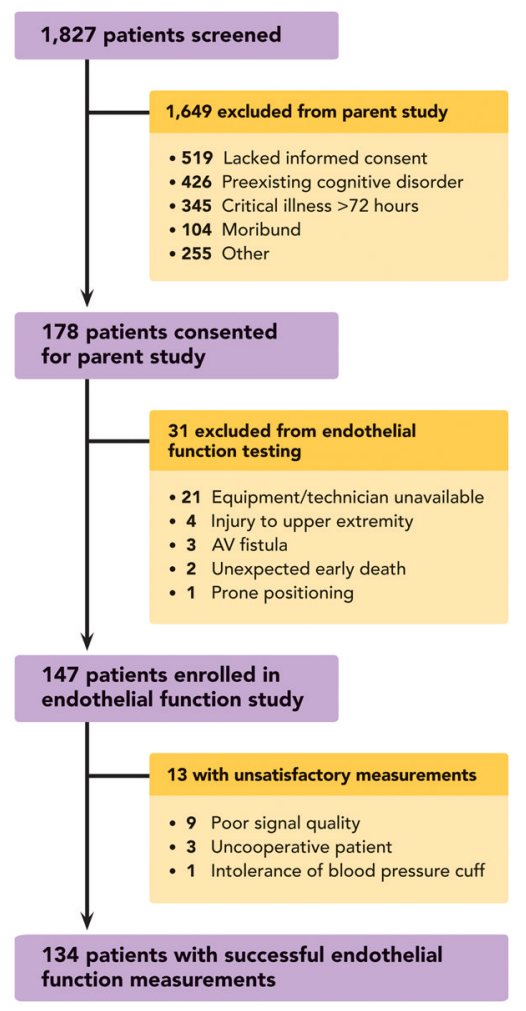

Figure 2. Diagram of Study Profile

Prospective cohort nested within a larger observational study evaluating long-term cognitive impairment after critical illness. 


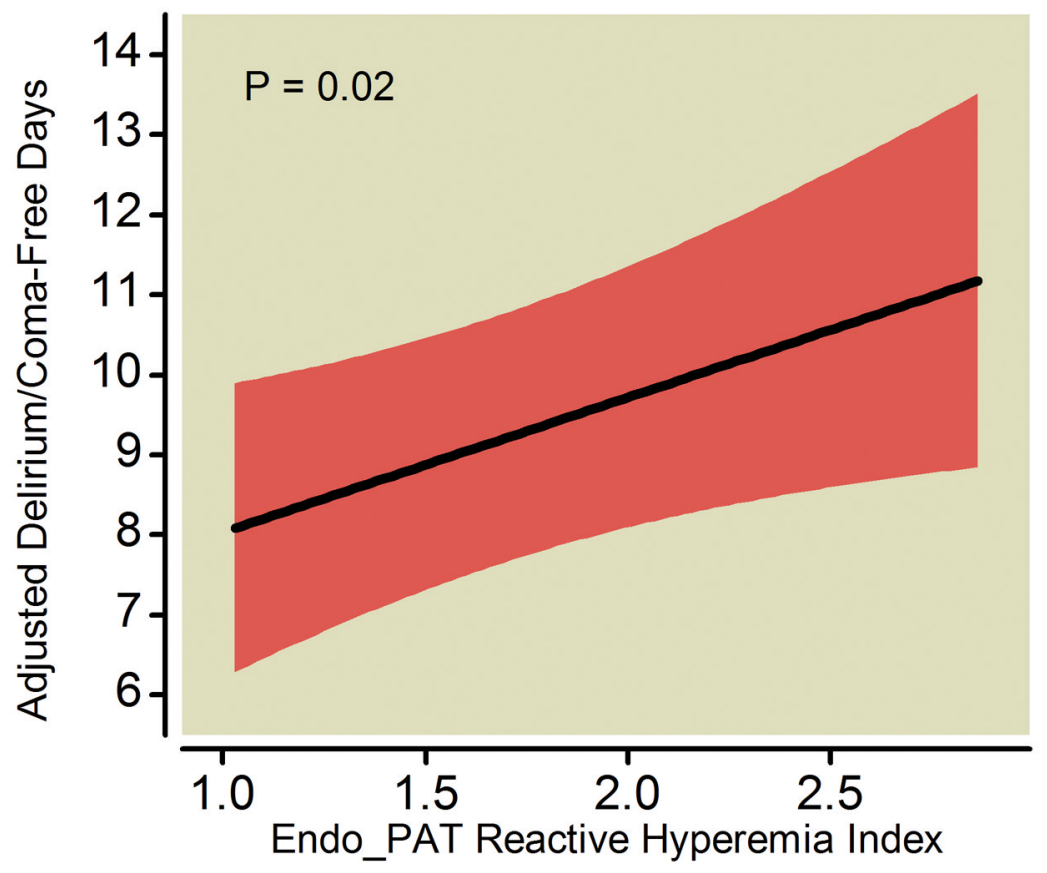

Figure 3. Endothelial Function versus Delirium/Coma-Free Days

Worse systemic endothelial function at enrollment (indicated by a lower Endo_PAT reactive hyperemia index, where $<1.67$ is considered endothelial dysfunction) was associated with fewer delirium/coma-free days among all patients after adjusting for covariates. The black line demonstrates the point estimate of the association between reactive hyperemia index and delirium/coma-free days, with the red ribbon indicating the $95 \%$ confidence interval. 


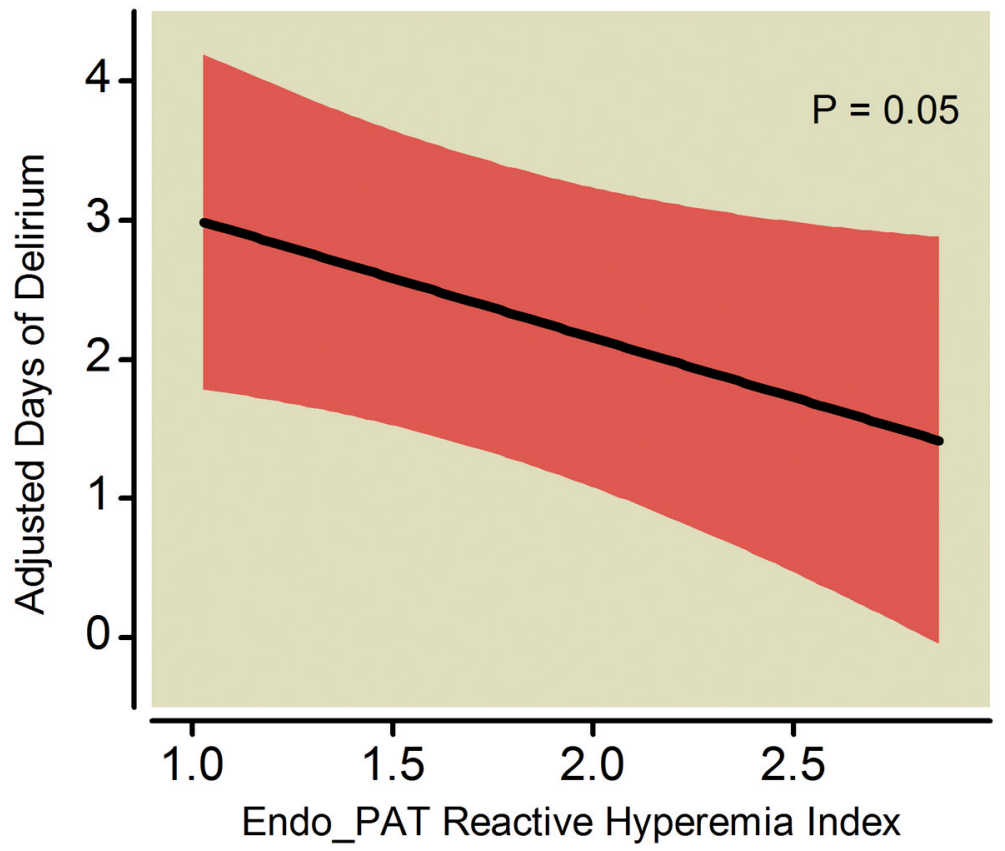

Figure 4. Endothelial Function versus Delirium Duration in Survivors

Worse systemic endothelial function at enrollment (indicated by a lower Endo_PAT reactive hyperemia index, where $<1.67$ is considered endothelial dysfunction) was associated with more days of delirium in survivors after adjusting for covariates. The black line demonstrates the point estimate of the association between reactive hyperemia index and days of delirium, with the red ribbon indicating the $95 \%$ confidence interval. 
Table 1

Demographic Characteristics and Outcomes of the Study Population

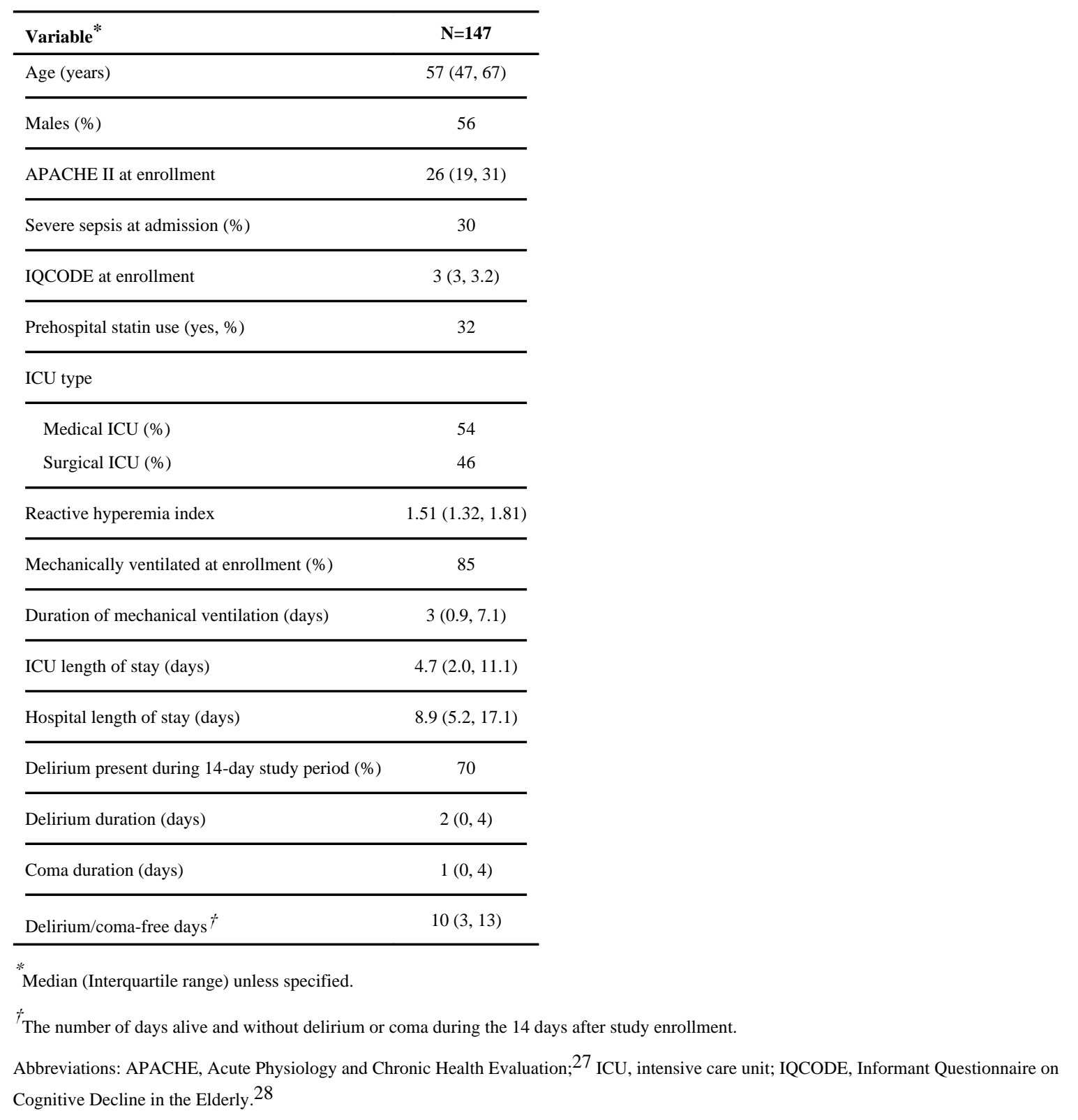


Table 2

Endothelial Dysfunction and Brain Dysfunction: Delirium/Coma-Free Days

\begin{tabular}{|c|c|c|c|c|}
\hline $\mathbf{N}=134$ & $25^{\text {th }}$ Percentile & $75^{\text {th }}$ Percentile & Adjusted Difference $25^{\text {th }}$ vs. $75^{\text {th }}(95 \% \text { CI })^{*}$ & P-value \\
\hline \multicolumn{5}{|l|}{ Independent Variable } \\
\hline - Reactive Hyperemia Index & 1.32 & 1.81 & $-0.8(-1.54,-0.12)$ & 0.02 \\
\hline \multicolumn{5}{|l|}{ Covariates } \\
\hline - Age (years) & 47 & 67 & $1.2(0.03,2.37)$ & 0.05 \\
\hline - APACHE APS & 17 & 27 & $2.2(1.11,3.35)$ & $<0.001^{\dagger}$ \\
\hline • ICU Type & Medical & Surgical & $0.5(-1.34,2.28)$ & 0.61 \\
\hline$\bullet$ IQCODE & 3.00 & 3.19 & $0.1(-0.42,0.53)$ & 0.83 \\
\hline - Prehospital Statin Use & No & Yes & $-0.4(-2.29,1.46)$ & 0.66 \\
\hline - Severe Sepsis & No & Yes & $1.2(-0.87,3.18)$ & 0.27 \\
\hline
\end{tabular}

Abbreviations: APACHE, Acute Physiology and Chronic Health Evaluation; ${ }^{27}$ APS, Acute Physiology Score; ICU, intensive care unit; IQCODE, Informant Questionnaire on Cognitive Decline in the Elderly. 28

Endothelial function, the independent variable, was assessed using the Endo_PAT (Itamar Medical Ltd, Franklin, MA) reactive hyperemia index (RHI), a validated assessment of systemic endothelial function where $<1.67$ is considered endothelial dysfunction. ${ }^{18 ; 19}$ Linear regression was used to study the association of endothelial function $(\mathrm{N}=134)$ with acute brain dysfunction after adjusting for age, acute physiology score of the Acute Physiology and Chronic Health Evaluation II, ${ }^{27}$ severe sepsis, Informant Questionnaire on Cognitive Decline in the Elderly 28 score, medical versus surgical ICU admission, and prehospital statin use. The adjusted difference represents the difference in delirium/coma-free days between the $25^{\text {th }}$ vs. the $75^{\text {th }}$ percentile for continuous variables or no vs. yes for dichotomous variables. Interpretative example: Other covariates being equal, patients with a RHI at the $25^{\text {th }}$ percentile (1.32, poor endothelial function) would have, on average, 0.8 fewer delirium/coma-free days than patients with a RHI at the $75^{\text {th }}$ percentile (1.81, good endothelial function). 
Table 3

Endothelial Dysfunction and Brain Dysfunction: Delirium Duration in Survivors

\begin{tabular}{|c|c|c|c|c|}
\hline$N=113$ & 25 ${ }^{\text {th }}$ Percentile & $7^{\text {th }}$ Percentile & Adjusted Difference $25^{\text {th }}$ vs. $75^{\text {th }}(95 \% \text { CI })^{*}$ & P-value \\
\hline \multicolumn{5}{|l|}{ Independent Variable } \\
\hline - Reactive Hyperemia Index & 1.32 & 1.81 & $0.4(0.00,0.86)$ & 0.05 \\
\hline \multicolumn{5}{|l|}{ Covariates } \\
\hline - Age (years) & 47 & 67 & $-1.5(-2.46,-0.51)$ & $0.01^{\dagger}$ \\
\hline - APACHE APS & 17 & 27 & $-1.0(-1.66,-0.24)$ & $0.008^{\dagger}$ \\
\hline • ICU Type & Medical & Surgical & $-1.1(-2.33,0.06)$ & 0.06 \\
\hline • IQCODE & 3.00 & 3.19 & $0.1(-0.23,0.35)$ & 0.71 \\
\hline - Prehospital Statin Use & No & Yes & $-0.2(-1.44,1.01)$ & 0.73 \\
\hline - Severe Sepsis & No & Yes & $-0.6(-1.95,0.67)$ & 0.34 \\
\hline
\end{tabular}

Abbreviations: APACHE, Acute Physiology and Chronic Health Evaluation; ${ }^{27}$ APS, Acute Physiology Score; ICU, intensive care unit; IQCODE, Informant Questionnaire on Cognitive Decline in the Elderly. ${ }^{28}$

Endothelial function, the independent variable, was assessed using the Endo_PAT (Itamar Medical Ltd, Franklin, MA) reactive hyperemia index (RHI), a validated assessment of systemic endothelial function where $<1.67$ is considered endothelial dysfunction. ${ }^{18 ; 19}$ Linear regression was used to study the association of endothelial function with duration of delirium in patients surviving to 14 days $(\mathrm{N}=113)$ after adjusting for age, acute physiology score of the Acute Physiology and Chronic Health Evaluation II, 27 severe sepsis, Informant Questionnaire on Cognitive Decline in the Elderly 28 score, medical versus surgical ICU admission, and prehospital statin use. This analysis was limited to survivors to avoid bias due to death. The adjusted difference represents the difference in delirium duration between the $25^{\text {th }}$ and $75^{\text {th }}$ percentile for continuous variables or no vs. yes for dichotomous variables. Interpretative example: Other covariates being equal, patients with a RHI at the $25^{\text {th }}$ percentile (1.32, poor endothelial function) would have, on average, 0.4 more days with delirium than patients with a RHI at the $75^{\text {th }}$ percentile $(1.81$, good endothelial function). 